\title{
Enseñar religión en la escuela: Aproximaciones a una noción de libertad de conciencia que abarque la enseñanza privada a la luz del fallo "Castillo"
}

Teaching religion in school: approaches to a notion of freedom of conscience that encompasses private teaching in light of the "Castillo" ruling Ensinar a religião na escola: Abordagens a uma noção de liberdade de consciência que abrange a educação privada à luz da sentença "Castillo"

Enseigner la religion à l'école: des approches vers une notion de liberté de conscience qui englobe l'enseignement privé, à la lumière du jugement "Castillo"

Ramiro Manuel Fihman ${ }^{1}$ | Universidad de Buenos Aires

Revista Derechos en Acción ISSN 2525-1678/ e-ISSN 2525-1686

Año 4/Nº 11 Otoño 2019 (21 marzo a 21 junio), 411-431

DOI: https://doi.org/10.24215/25251678e283

ORCID: https://orcid.org/0000-0001-6999-6473

Recibido: 29/03/2019

Aprobado: 18/05/2019

Resumen: El fallo "Castillo" de la Corte Suprema de Justicia de la Nación, del año 2017, constituye un precedente relevante para Argentina en materia de libertad religiosa. A grandes rasgos determinó que no está permitida la enseñanza religiosa en escuelas públicas durante horario de clase. Sin embargo, no parece estar demasiado claro por qué la prohibición de enseñar religión en la escuela sólo alcanza a las instituciones públicas. De hecho, varios de los argumentos empleados por

Estudiante de Abogacía (UBA).

Correo electrónico de contacto: ramirofihman@gmail.com. 
el máximo tribunal para defender la laicidad de la educación pública son aplicables también al ámbito privado. En ese sentido, cabe preguntarse qué fundamentos existen para excluir a los/as niños/as que asisten a una escuela privada -decisión que no depende de ellos/as- del derecho a la libertad de conciencia.

Palabras claves: enseñanza - religiosa - escuelas - publicas - privadas libertad - conciencia - niños - castillo

Abstract: The "Castillo" ruling of the Supreme Court of Justice of the Nation, in 2017, constitutes a relevant precedent for Argentina in matters of religious freedom. It broadly determined that religious instruction is not permitted in public schools during class hours. However, it does not seem to be very clear why the prohibition of teaching religion in school only reaches public institutions. In fact, several of the arguments used by the highest court to defend the secularity of public education are also applicable to the private sphere. This raises the question of what grounds exist for excluding children who attend a private school - a decision that does not depend on them - from the right to freedom of conscience.

Keywords: Teaching-religious-schools-public-private-freedom-conscience-children-castle.

Resumo: A sentença "Castillo" do Supremo Tribunal de Justiça da Nação, do ano 2017, constitui um precedente relevante para a Argentina em matéria de liberdade religiosa. Em geral, determinou que não está permitida a educação religiosa nas escolas públicas durante o horário escolar. No entanto, não parece estar muito claro por que a proibição de ensinar religião nas escolas só atinge instituições públicas. De fato, vários dos argumentos usados pelo Supremo Tribunal para defender a secularidade da educação pública também são aplicáveis à esfera privada. Nesse sentido, posso perguntar que fundamentos existem para excluir as crianças que assistem a uma escola particular - decisão que não depende dos/ das - do direito à liberdade de consciência.

Palavras-chave: ensino - religiosa - escolas - públicas - privadasliberdade - consciência - criança - castelo.

Résumé: Le jugement "Castillo" de la Cour Suprême de Justice de la Nation de 2017, constitue un précédent important pour l'Argentine en matière de liberté religieuse. Dans des grandes lignes, il a déterminé 
que l'éducation religieuse n'est pas autorisée dans les écoles publiques pendant les heures de classe. Pourtant, il n'apparaît pas très claire la raison pour laquelle l'interdiction d'enseigner la religion à l'école ne comprend que les institutions publiques. En fait, plusieurs des arguments invoqués par la Cour pour défendre la laïcité de l'enseignement public s'appliquent également à la sphère privée. En ce sens, on peut se demander: quels sont les fondements pour exclure les enfants qui fréquentent une école privée - décision qui ne dépend pas d'eux - du droit à la liberté de conscience.

Mot-clés: Enseignement - religieux - écoles - public - privé - liberté conscience - enfants - Castillo

\section{Introducción}

Nuestro país se encuentra atravesando un momento de fuertes cuestionamientos respecto de la influencia de la religiosidad en la cosa pública. En ese sentido, en los últimos años se han puesto en jaque distintos aspectos de esta situación, como por ejemplo la criminalización de la interrupción voluntaria del embarazo o la enseñanza religiosa en escuelas públicas.

El reciente fallo de la CSJN en el caso "Castillo, Carina Viviana y otros c/ Provincia de Salta- Ministerio de Educación de la Prov. de Salta s/ amparo", del 12 de diciembre de 2017 declaró, entre otras cosas, la inconstitucionalidad de la norma provincial de Salta que permitía la enseñanza de religión en horario de clase en escuelas públicas de la provincia.

Sin embargo, es curioso que en Argentina prácticamente no ha sido cuestionada la educación religiosa si ésta se da en el marco de una escuela de gestión privada. Partiendo de la base de que los/as niños/as siguen siendo niños/as sin importar a qué tipo de escuela los/as manden sus padres/madres, es necesario tener en cuenta la relevancia de la temática: según datos del año 2009 proporcionados por el Ministerio de Educación, hay aproximadamente 3,5 millones de niños/as en escuelas primarias de gestión estatal y 1,1 millones de niños/as en escuelas 
primarias de gestión privada. ${ }^{2}$ Esto implica que casi un $25 \%$ de los/as niños/as de escuela primaria asisten a una institución de gestión privada.

En este orden de ideas, la reciente decisión de la Corte Suprema en relación a que no está permitido dictar religión en horario de clase, sólo rige para tres cuartas partes de los/as niños/as de nuestro país. Los/as otros/as pueden recibir este tipo de contenidos sin ningún tipo de limitaciones, siendo suficiente la decisión de los/as padres/madres de enviarlos/as a una escuela privada que profese la religión a la que adhieren.

Ahora bien, si los sujetos de derecho que se ven afectados por el hecho de que se impartan contenidos de religión en las escuelas son los/as niños/as, y el principal argumento para justificar la lesión está basado en el derecho a aprender, el derecho a la libertad de conciencia, el derecho a la igualdad y el derecho a la autonomía, ¿cómo es posible realizar una diferenciación entre los/as niños/as que asisten a una escuela pública y los/as que asisten a una privada? ¿Acaso los/as niños que asisten a las segundas carecen de estos derechos? ¿Con qué fundamento? Según la CSJN, los convencionales constituyentes acordaron que la laicidad de la educación pública busca "asegurar la promoción de los valores democráticos y la igualdad de oportunidades y posibilidades sin discriminación alguna"; 3 también el tribunal sostiene que "debe garantizarse la posibilidad de un pluralismo educativo que asegure que las informaciones y conocimientos que figuran en el plan de estudios se difundan de manera que los alumnos desarrollen un sentido crítico respecto del fenómeno religioso en una 'atmósfera serena preservada de todo proselitismo" "4 ¿ ¿No aplica acaso esto a los/as niños/as que no asisten a escuelas del Estado?

\footnotetext{
2 Informe CIMientoS - Fundación para la Igualdad de Oportunidades Educativas, La educación argentina en números, abril de 2011, pp. 5-6.

3 CSJN, "Castillo, Carina Viviana y otros c/ Provincia de Salta- Ministerio de Educación de la Prov. de Salta s/ amparo", sentencia del 12 de diciembre de 2017, p. 14.

4 Ibid., p. 30.
} 
La distinción público/privado es un punto recurrente para establecer ciertos presupuestos relativos a las libertades individuales. Quienes son dueños/as de empresas, por ejemplo, suelen ampararse en el carácter privado de éstas para justificar decisiones acorde a su moral o a sus creencias religiosas. No caben dudas de que el dueño de un restaurant tiene derecho a colocar un crucifijo en la entrada del establecimiento si así lo desea. Los/as clientes pueden decidir concurrir o no a un lugar de estas características. Pero el punto clave es el siguiente: los/as niños/as no pueden decidir a qué escuela van a asistir.

Más allá que pueda reflexionarse al respecto, no resulta controvertible el hecho de que en el Derecho Internacional de los Derechos Humanos se encuentra consagrado el derecho de los padres a decidir si a sus hijos se les impartirá una determinada enseñanza religiosa (art. 13.3 PIDESC, art. 12.4 CADH, art. 18.4 PIDCP). Sin embargo, estas normas no hablan de que los/as niños/as deban recibir esa educación en la escuela. La formación en una determinada religión o moral -generalmente, la que profesan los padres- puede darse (y de hecho así ocurre en la mayoría de los casos) en muchos otros ámbitos, específicamente pensados para ello (la iglesia, sinagoga, parroquia, o lo que fuere). Pero no surge de los tratados internacionales que los padres puedan "mezclar" el derecho a la educación de sus hijos con sus creencias religiosas.

A partir de estos interrogantes, el objetivo de este trabajo es dilucidar los argumentos jurídico-políticos que sustentan la hipótesis de que la práctica de impartir educación religiosa resulta inconstitucional, sin importar si se trata de una institución de gestión estatal o de gestión privada. ${ }^{5}$ Para ello, se analizarán en primer lugar las principales herramientas empleadas por la

5 Tampoco se realizarán distinciones relativas al horario en el que se imparten contenidos religiosos. Considero que no es relevante si éstos se dan dentro o fuera del horario de clases, entre otras cosas, porque las "clases" entendidas en términos formales no son lo único que constituye la enseñanza religiosa sino que generalmente viene acompañada de simbolismos, costumbres y prácticas que vulneran igualmente los derechos en juego. 
Corte en el fallo "Castillo" sobre las cuales pueden encontrarse determinadas falencias o problemas de consistencia; luego, se propondrán los derechos que se encontrarían en juego al discutir la cuestión de la enseñanza religiosa, y las distinciones -si las hay- que podrían hacerse entre escuelas públicas y privadas; en tercer lugar, se tratará la cuestión del principio de igualdad y cómo opera para el tema de análisis; por último se elaborarán conclusiones.

\section{Los argumentos de "Castillo"}

El objetivo de este apartado es analizar la compatibilidad o no de los principales argumentos esbozados en el fallo de la Corte Suprema con un supuesto de hecho en el que los niños asisten a una escuela privada. Las razones por las que se esgrime que la enseñanza privada también debería ser laica no se agotan analogía de los argumentos utilizados por la Corte, sino que tienen que ver fundamentalmente con el involucramiento de derechos partiendo de una noción robusta de la igualdad y el interés superior del niño, como se explicará en el próximo apartado. Sin embargo, se mostrarán algunos ejemplos que demuestran, en cierto grado, ciertas inconsistencias en los criterios adoptados.

Uno de los ejes fundamentales del fallo "Castillo" consiste en la neutralidad religiosa del Estado. A partir de una interpretación del artículo $2^{\circ}$ de la Constitución, en armonía con los tratados internacionales de Derechos Humanos, la Corte reitera que ningún culto es la religión oficial de Argentina, siendo éste un país laico. En materia de educación, analiza los debates de la Convención Constituyente, destacando el carácter laico de la educación pública con el fin de "asegurar la promoción de los valores democráticos y la igualdad de oportunidades y posibilidades sin discriminación alguna". ${ }^{6}$ Asimismo, cita al Comité de Derechos Humanos en su Observación General No 22, según el cual “... la educación obligatoria que incluya el adoctrinamiento

6 Fallo "Castillo", consid. 13, párr. 4. 
en una religión o unas creencias particulares es incompatible con el párrafo 4 del artículo 18, a menos que se hayan previsto exenciones y posibilidades que estén de acuerdo con los deseos de los padres o tutores." 7 En este sentido, es posible afirmar que, por el momento, no se deriva de estos argumentos ningún elemento que permita realizar una distinción entre escuelas privadas y escuelas públicas. Más aún, podría decirse que el riesgo de que en una escuela privada se den prácticas violatorias de estos preceptos es mucho más alto que en una escuela pública, por la falta de presencia del Estado, que debería ser el que asegure la neutralidad.

La Corte analiza el principio de igualdad con un estándar basado en la protección mediante acciones positivas de grupos históricamente desaventajados. Para el caso, el grupo en cuestión, según el fallo, son "los niños y niñas que no integran el grupo religioso predominante”. Sería absurdo asumir que este grupo está compuesto sólo por aquellos niños que asisten, por distintas circunstancias, a una escuela pública. Los niños que asisten a escuelas privadas en que se enseña una religión en particular que ellos no profesan también ven vulnerados sus derechos. No obstante, a lo largo de este artículo, sostendré que no son sólo aquellos niños que no profesan la religión enseñada en la escuela quienes ven vulnerados sus derechos, sino todos los niños en general. Más aún, los argumentos que sostiene la Corte tendientes a reconocer la laicidad de la educación no deberían buscar proteger la libertad de culto de aquellos niños que no integran el grupo religioso predominante, sino la libertad de conciencia y la autonomía progresiva de los niños en su conjunto.

Otro de los puntos de la Corte gira en torno al formulario de exención creado por Disposición 45/09, que debían completar los padres del niño que deseaban que a su hijo no se le imparta religión, o se le imparta alguna otra en particular. El máximo tribunal sostiene la invalidez de este formulario por razones

7 Observación General N² 22 del Comité de Derechos del Hombre de las Naciones Unidas sobre la interpretación del artículo 18 del PIDESC, del 20/07/1993. 
de derecho a la privacidad (artículo 19 de la Constitución). ¿No tiene derecho a la privacidad un niño que asiste a una escuela privada? Si quisiera que no se le enseñe religión en una escuela privada ¿debería también declararlo explícitamente, revelando asuntos de su esfera personal en la que el Estado no puede meterse? Si la respuesta es afirmativa, entonces estamos diciendo que el derecho a la intimidad termina en el momento en que un privado decide gestionar una institución educativa; y que el Estado no puede interferir en esa esfera privada, pero sí puede hacerlo una escuela privada.

El artículo 13 del PIDESC expresa que “... la educación debe orientarse hacia el pleno desarrollo de la personalidad humana y del sentido de su dignidad, y debe fortalecer el respeto por los derechos humanos y las libertades fundamentales. Convienen asimismo en que la educación debe capacitar a todas las personas para participar efectivamente en una sociedad libre, favorecer la comprensión, la tolerancia y la amistad entre todas las naciones y entre todos los grupos raciales, étnicos o religiosos, y promover las actividades de las Naciones Unidas en pro del mantenimiento de la paz" y asimismo, el Comité de Derechos Económicos, Sociales y Culturales, ha establecido en su Observación General No 13 que "Los Estados Partes han de velar por que los planes de estudio, en todos los niveles del sistema educativo, estén orientados a los objetivos definidos en el párrafo 1 del artículo 13. Asimismo, tienen la obligación de establecer y mantener un sistema transparente y eficaz para comprobar si la educación se orienta o no realmente a los objetivos educativos que se exponen en el párrafo 1 del artículo 13." ${ }^{8}$ Cabe preguntarse, en este orden de ideas, si es posible garantizar las previsiones del artículo 13, interpretado por el Comité, en una escuela en donde sólo se enseña un dogma incuestionable como una verdad absoluta. Para fomentar la

8 Observación General № 13 del Comité de Derechos Económicos, Sociales y Culturales de la Organización para las Naciones Unidas sobre la interpretación del Artículo 13 del PIDESC, del 8/12/1999, párr. 49. 
comprensión, tolerancia y amistad entre todos los grupos religiosos, pareciera no ser suficiente el hecho de no inculcarles a los niños que las otras religiones son malas, sino que debería fomentarse un espíritu crítico y diverso, que permita a todos decidir su culto y aceptar el del otro.

La CSJN, ya entrando de lleno en la cuestión de la libertad religiosa en materia educativa, sostiene -citando jurisprudencia del Comité Europeo de DDHH- que "debe garantizarse la posibilidad de un pluralismo educativo que asegure que las informaciones y conocimientos que figuran en el plan de estudios se difundan de manera que los alumnos desarrollen un sentido crítico respecto del fenómeno religioso en una 'atmósfera serena preservada de todo proselitismo”. Sin embargo, no fundamenta por qué estas previsiones, que tienen -nuevamente- por fin proteger los derechos de los niños, sólo se aplicarían para un grupo de éstos, dejando afuera a muchos otros que no pudieron decidir ir a una escuela o a otra.

\section{Los derechos en juego}

Luego de analizar algunos puntos que muestran la factibilidad de asimilar los planteos de la laicidad de escuelas públicas con las escuelas privadas, resta realizar algunos comentarios en relaciona los derechos que están en juego en lo que respecta a la enseñanza religiosa, más allá de lo que finalmente haya tenido en cuenta el máximo tribunal a la hora de dictar la sentencia para este caso particular.

\section{III.A. Autonomía personal del niño y libertad de conciencia}

El principio de autonomía, en términos generales, constituye un concepto largamente trabajado por la filosofía política y el Derecho, y no resulta sencillo esbozar una definición que conforme a la totalidad de los autores que lo han investigado. En principio, puede decirse que, normativamente, se desprende del artículo 19 de nuestra Constitución Nacional, y de diversos tratados internacionales que adquirieron jerarquía 
constitucional en Argentina en 1994. Carlos Nino define este principio como aquel que prescribe que "siendo valiosa la libre elección individual de planes de vida y la adopción de ideales de excelencia humana, el Estado (y los demás individuos) no debe interferir en esa elección o adopción, limitándose a diseñar instituciones que faciliten la persecución individual de esos planes de vida y la satisfacción de los ideales de virtud que cada uno sustente e impidiendo la interferencia mutua en el curso de tal persecución."9 En ese sentido, puede verse que, a grandes rasgos, la autonomía se desprende de una concepción previa de que todos somos libres de elegir el curso de nuestras acciones $\mathrm{y}$, siempre y cuando no perjudiquemos a otros, nadie puede entrometerse en ello. Además, esto conlleva que el Estado debe actuar positivamente para que todos podamos alcanzar nuestro plan de vida.

Ahora bien, este principio, que resulta troncal para el desarrollo de una sociedad liberal, no es aplicable de forma tan directa a cualquier grupo de personas. Está claro que la autonomía personal, cuando hablamos de personas con severas discapacidades mentales, por ejemplo, merece especiales consideraciones. Lo mismo ocurre cuando se desea analizar cuál es la autonomía de la que deben gozar los niños y cuál es el mecanismo para garantizarla. En otras palabras ¿nadie debe interferir en la vida de ningún niño? ¿qué ocurre con las decisiones que toman sus padres para su vida? ¿y el Estado, mediante las escuelas o los planes de vacunación? ¿es un niño realmente capaz de discernir qué desea como plan de vida?

Históricamente se consideró a los niños como un objeto de protección por parte del Derecho. ${ }^{10}$ Con esa lógica, resulta prácticamente imposible pensar una genuina autonomía, en cualquiera de sus formas y niveles, puesto que quien es incapaz de decidir por ser un objeto que debe protegerse, no puede

9 Nino, Carlos S., Ética y derechos humanos, Buenos Aires, Astrea, 2 ed., 1989, pp. 204-205.

10 Faerman, Romina, Ministerio Público Tutelar de la CABA, Las decisiones de los niños, niñas y adolescentes a la luz del principio de autonomía personal, Documento de trabajo $N^{0}$ 6, p. 4. 
tener derecho a ser autónomo. Fue recién con la Convención Internacional sobre los Derechos del Niño que se superó este paradigma, para comenzar a considerar a los niños como sujetos de derecho. ${ }^{11}$ Pero además, esta convención reconoce, en su artículo $5^{\circ}$, que los niños adquieren autonomía de forma progresiva de acuerdo a sus facultades, contrariamente a la clásica concepción de que esto se producía de forma automática al alcanzar la mayoría de edad. Esta idea, de "autonomía progresiva" implica también que la orientación o dirección que puedan brindarle a un niño quienes estén a cargo de su cuidado tiene por fin lograr que éste logre ejercer adecuadamente sus derechos. En ese sentido cabe preguntarse hasta qué punto la decisión de enviar a un niño a una escuela religiosa, en donde no se le presentan otras alternativas posibles para su cosmovisión, representa un límite válido a la autonomía personal. ¿puede realmente el niño elegir su plan de vida entre distintas opciones posibles?

Surge de aquí un elemento a tener en cuenta en este plano, que es la antiguamente llamada "patria potestad", concepto superado en la actualidad por la legislación argentina, pero que entraña aquel poder que los padres tienen sobre un niño -en principio, hasta cierta edad- para decidir sobre la gran mayoría de los aspectos de su vida. Sin embargo, lógicamente, los padres no son dueños de sus hijos, ${ }^{12}$ sino que el límite a este poder está claro: no forma parte de la patria potestad aquello que afecte irreversiblemente la autonomía potencial del niño. ${ }^{13}$ Es cierto que el Derecho Internacional de los Derechos Humanos protege el derecho de los padres a decidir ciertos aspectos de la educación -en sentido amplio- de sus hijos. Sin embargo, nada dicen las normas internacionales sobre el hecho de que esa educación se de en el marco de la enseñanza obligatoria.

\footnotetext{
11 Ibid.

12 Nino, Carlos S., Fundamentos de Derecho Constitucional, 4ta Ed., Buenos Aires, Astrea, 2013, p. 294.

13 Ibid.
} 
Aquello que el Estado requiere en el territorio nacional (educación inicial, primaria y secundaria) no está incluido en la libertad de los padres en relación a la "enseñanza". En otras palabras, es imposible evitar que los padres críen a sus hijos en el marco de determinado culto, pero lo que sí podemos evitar como sociedad es que esa formación se de en la escuela, que es el ámbito en donde se gestan las características más esenciales en la personalidad de una persona, que luego debería poder participar del debate público con elementos democráticos deliberativos, basados en un pensamiento crítico genuino.

De la autonomía personal se desprende, entre muchos otros derechos, la libertad de conciencia, ${ }^{14}$ consagrada en el artículo 12 de la Convención Americana sobre Derechos Humanos. Esto implica, según la propia norma, la libertad de conservar su religión o sus creencias, o de cambiar de religión o de creencias, así como la libertad de profesar y divulgar su religión o sus creencias, individual o colectivamente, tanto en público como en privado. Lo que nos importa esencialmente para este trabajo es la libertad de profesar -o no hacerlo- el propio culto. La pregunta central, entonces, sería: ¿ejerce una persona la libertad de profesar -o no- el culto si desde su más temprana edad es enviada a una escuela que imparte religión? ¿qué tan determinada estará su creencia y qué tan abierta estará la persona a darse la posibilidad de acercarse a otros cultos o de decidir no profesar ninguno? Algunos de estos interrogantes exceden la cuestión jurídica, siendo necesario abarcar otras disciplinas como la psicología, la pedagogía o incluso la sociología.

\section{III.B. Derecho a una educación ¿liberal?}

Habiendo esbozado rápidamente el concepto de autonomía, resulta necesario pensar cuáles son los factores elementales que permiten que una persona sea autónoma en su vida. Sin lugar a dudas uno de ellos es la educación. Nuevamente en palabras de

14 Ibid, p. 280. 
Nino, “... la educación es esencial para la posibilidad de elegir libremente planes de vida e ideales del bien. Por el otro lado, una determinada educación es necesaria para materializar el plan de vida o el ideal del bien libremente elegido." 15

Sin embargo, no cualquier tipo de educación resulta beneficiosa para el desarrollo de la autonomía de una persona ni es funcional para que ésta pueda elegir su plan de vida. A modo de intuición, puede decirse que una educación dogmática y/u oscurantista, poco tendría que aportar a un proyecto de vida autónomo libre de interferencias. ${ }^{16}$ La permeabilidad de los niños respecto de la información que reciben en sus primeros años de vida los hace especialmente susceptibles a lo que les presentan como verdad. ${ }^{17}$

Se presenta entonces el siguiente interrogante: ¿qué características debe tener la educación para que podamos afirmar que se encuentra garantizado el derecho? El concepto clave aquí es el de neutralidad: la enseñanza debe ser lo más neutral posible, dentro del marco de los valores de autonomía personal y democracia; neutral respecto de aquellas decisiones de vida que deben ser tomadas en una esfera individual. ${ }^{18}$ En ese sentido, no puede la escuela meterse en la identidad sexual de un niño, ni decirle cuál debe ser su comida o su deporte favoritos, como tampoco puede un docente obligarlo a que su "prócer" favorito sea uno en particular. Pero neutralidad no significa silencio; es necesario que la neutralidad implique la enseñanza

\footnotetext{
15 Ibid, p. 293.

16 No pretendo con esto decir que la educación de cierto culto necesariamente tenga esas características.
}

17 Esto constituye una interesante discusión en el campo de las ciencias de la educación y la psicología. Jorge Larrosa trabaja el significado de la "verdad" en la infancia, y explica que en ese momento, lo verdadero no se contrapone -como ocurre en la vida adulta con un paradigma científico- al error o a la falsedad, sino que simplemente se opone al ocultamiento, al engaño y al olvido: "...la verdad no es adecuación epistémica sino imperativo moral" (LARRosa, Jorge, Pedagogía profana. Estudios sobre lenguaje, subjetividad, formación, Buenos Aires, Ediciones Novedades Educativas, 2000, p. 176).

18 Nino, Carlos S., Fundamentos de Derecho Constitucional, p. 295. 
de una amplia gama de conocimientos. Esto es aplicable a, prácticamente, cualquier temática: los niños deben recibir distintas versiones de la historia, distintas versiones de las teorías matemáticas ${ }^{19}$, distintas versiones de la evolución humana, entre muchos otros. Desde esta lógica -analítica, plural, libre de dogmas- podría estar comprendida la religión, que constituye un tema central para la humanidad, y debe ser conocido por todos para poder decidir si profesar o no un credo.

Sin embargo, hablar de neutralidad parece no ser suficiente. Amy Gutmann explica que hay tres "modelos" predominantes en relación con la neutralidad de la enseñanza: el primero es el del "Estado familiar", que acepta y defiende la idea de que el Estado puede arrogarse la potestad de imponer a los estudiantes las nociones del bien y del mal que considere correctas; el segundo es el "Estado de familias", que le concede a los padres el derecho absoluto sobre la educación de sus hijos; y por último el "Estado de individuos", que supone que no debe educarse bajo ninguna concepción moral sino sólo brindando elementos neutrales. La autora rechaza las dos primeras concepciones y es escéptica respecto de la última, ya que sostiene que no existe una educación completamente neutral, puesto que siempre se impartirán nociones morales aún encubiertas. ${ }^{20}$ En ese orden de ideas propone la noción de "Estado democrático", que es analizada por $\mathrm{Nino}^{21}$ desde un punto de vista crítico, pero acordando que el proceso educativo debe tener en miras la participación de las personas en el proceso democrático. El punto de partida en esta línea gira en torno a aceptar que el Estado tiene el deber de establecer los contenidos mínimos que

\footnotetext{
19 Nótese, por ejemplo, cómo durante la última dictadura cívico-militar argentina, en matemáticas no se enseñaba la llamada "teoría de los conjuntos" por el temor del gobierno de que esto sirviera como una herramienta política para la organización estudiantil. Cfr. PInEAU, Pablo, "Reprimir y discriminar. La educación en la última dictadura cívico-militar en Argentina (1976-1983)" Educar em Revista, Curitiba, Brasil, n. 51, p. 103-122, 2014. Editora UFPR.

20 Gutmann, Amy, Democratic Education, New Jersey, Princeton University Press, pp. 19-41.

21 Nino, Carlos S., Fundamentos de derecho constitucional, pp. 294-296.
} 
permitan desarrollar la autonomía que, a su vez, es precondición de ciudadanía (en un estado liberal). ${ }^{22}$

Pero ¿cómo armonizar la elección de los padres de que sus hijos profesen su culto y la necesidad de una educación que promueva valores democráticos, para los cuales es ineludible cierto grado de neutralidad? Gutmann considera que esto es posible, sencillamente requiriendo que las escuelas privadas religiosas enseñen el conjunto de valores democráticos necesarios para el desarrollo de la ciudadanía de los niños. ${ }^{23}$ A pesar de ello, lo cierto es que este razonamiento puede resultar algo insuficiente: ¿es liberal una educación que, aún enseñando los valores democráticos fundamentales, imparte una religión como un dogma a niños que aún no tienen su capacidad crítica enteramente desarrollada?

\section{III.C. Derecho a enseñar ¿cualquier cosa?}

El artículo 14 de la Constitución reconoce, además del derecho a aprender, el derecho a enseñar (de hecho, "enseñar" precede a "aprender" en la redacción). A priori, pareciera no presentar demasiados problemas el hecho de que exista un derecho a enseñar; en efecto, puede interpretarse como algo bastante lógico. Sin embargo, con apenas adentrarse en la problemática, aparecen tensiones muy difíciles de despejar. ¿Qué abarca el derecho a enseñar? ¿Quién es el titular de este derecho? ¿Qué ocurre cuando lo que se quiere enseñar no es lo que debe ser aprendido? ¿En qué medida puede un docente apartarse de los conocimientos que los planes de estudio le imponen?

Lejos de ser "dos caras de una misma moneda" puede decirse que el derecho a enseñar y el derecho a aprender representan un pragma conflictivo. De la misma forma que se presenta el derecho a huelga para defender otros derechos como el trabajo,

22 SABA, Roberto, "Igualdad de trato entre particulares", en Lecciones y Ensayos, Departamento de Publicaciones de la Facultad de Derecho de la UBA, Nº 89, 2011, pp. 217-276.

23 Gutmann, Amy, Democratic..., ob. cit. p. 117. 
el derecho a la enseñanza debe ser entendido como un medio para satisfacer el derecho a la educación. ${ }^{24}$ Está claro que no aceptaríamos la idea de un escenario en el que está garantizado el derecho a enseñar pero no el derecho a aprender.

Según el Comité DESC, el derecho a enseñar tiene dos elementos principales. El primero tiene que ver con la libertad de que los padres elijan la educación religiosa o moral de sus hijos. Sin embargo, en la ya citada Observación General No 13 , el Comité destaca que esto sólo es así siempre y cuando se impartan de forma imparcial y objetiva, que respete la libertad de opinión, de conciencia y de expresión. ${ }^{25}$ El segundo elemento tiene que ver con las alternativas educativas que no son escuelas públicas. Es decir, está relacionado con el derecho de un privado de impartir enseñanza. Este segundo punto está íntimamente relacionado con la idea de "libertad académica" y de "autonomía de las instituciones", que básicamente implica que las instituciones de enseñanza deben estar libres de presiones políticas o de otra índole que pudieran influir en los contenidos o en la forma de impartirlos.

A pesar de que es cierto que existe la libertad académica, va de suyo que este derecho, como cualquier otro, no es absoluto. Los límites parecen estar dados por la autonomía propia de los niños que -en términos tradicionales- serían el sujeto pasivo del ámbito educativo. No puede un docente, o una institución, comportarse de una manera que viole arbitrariamente el plan de vida del niño. Como los niños no se encuentran aún en condiciones de dilucidar con demasiada especificidad las características de su plan de vida, hay elementos que debemos proteger, y que tienen que ver con la participación democrática.

\footnotetext{
24 Feldfeber, Myriam, “¿Es pública la escuela privada? Notas para pensar en el Estado y en la educación" en PerazzA, Roxana (Dir.), Mapas y recorridos de la educación de gestión privada en la Argentina, Buenos Aires, Aique, 2012, p. 176.

25 Observación General № 13 del Comité de Derechos Económicos, Sociales y Culturales de la Organización para las Naciones Unidas sobre la interpretación del Artículo 13 del PIDESC, del 8/12/1999, párr. 28.
} 
En este orden de ideas, hay determinadas acciones que, realizadas por un docente, pueden afectar irreversiblemente los derechos en desarrollo del niño. Un ejemplo de esto podría ser perfectamente una escuela religiosa. Cuando una institución, en ejercicio de su derecho al autogobierno y a la libertad de enseñanza, imparte una visión del mundo -o del desenvolvimiento en la vida social- que es incompatible con la tolerancia, con el pensamiento crítico, ente otros. No puede un docente de matemáticas, aduciendo su derecho a enseñar, decirle a sus alumnos que 2 más 2 es igual a 5. Tampoco puede el director de una escuela obligar a un niño a estar encerrado en un cuarto sin luz como castigo por no hacer la tarea. No puede una maestra de primer grado darle actividades a los niños que vayan en contra de valores solidarios, obligándolos a competir agresivamente entre ellos y destacarse a costa de los demás. No pueden enseñarles a desacreditar a los demás o a no escuchar al que piensa distinto. Así, no puede tampoco un sacerdote que da clases de historia enseñarle a los niños en su escuela que Jesús volvió de la muerte, que Moisés dividió las aguas, o que la mujer nació de la costilla del hombre.

\section{El problema de la igualdad}

¿Por qué resulta problemático que se establezca una diferencia entre las escuelas públicas y las privadas? ¿Toda distinción de este tipo es discriminatoria? Está claro que pueden hacerse distinciones de cierto tipo, y de hecho como sociedad avalamos numerosas prácticas que implican tratos desiguales en relación a la niñez: quienes van a una escuela pública deben usar un guardapolvo blanco, mientras que los que van a una escuela privada lucen elegantes uniformes -lo que no necesariamente es positivo para los niños- o bien se les permite no utilizar ninguno; los que van a una escuela privada, generalmente tienen opciones extracurriculares que incluyen una amplia gama de actividades, etc. Pero estas distinciones -más allá de lo que pueda objetarse en relación a la influencia del sistema 
capitalista en ellas- no tienen una implicancia directa en la vida democrática de las personas.

Sin embargo, hay distinciones que no podemos tolerar, porque están directamente relacionadas con lo que los niños luego serán capaces de hacer en relación a la vida y a la deliberación públicas. La cuestión de la enseñanza religiosa es una de ellas: no podemos permitir que algunos niños estén libres de intromisiones en su cosmovisión y otros no. Frente a esto podría objetarse que quienes pertenecen a familias religiosas igualmente tendrán una inevitable formación en el culto de su familia o en la iglesia respectiva; eso es cierto, pero el hecho de que esto no esté sumado a la impartición de religión en el ámbito escolar implica un fuerte avance desde una perspectiva de Derechos Humanos.

Si tomamos un caso como ejemplo, en la Ciudad Autónoma de Buenos Aires, aproximadamente un $47 \%$ de los niños asisten a escuelas privadas. ${ }^{26}$ Esto significa que en esta ciudad, la mitad de los niños no gozan de una protección jurídica suficiente en relación a su libertad de conciencia. Esto no significa que la mitad de los niños asisten a una escuela confesional, sino que, al asistir a una escuela de gestión privada, podrían ser susceptibles de educación religiosa sin ningún tipo de límite ni matiz. No es menor señalar que, a pesar de existir escuelas privadas laicas, lo cierto es que la explicación histórica de la existencia de la escuela privada radica en la concepción del Estado y la Iglesia como dos esferas de poder separadas, que tenían su propio ámbito de formación independiente. ${ }^{27}$ De hecho, hay un elemento fundamental a tener en cuenta: el $70 \%$ de las escuelas de gestión privada del país reciben un subsidio estatal y, a su vez, el $63 \%$ de las escuelas privadas son confesionales. ${ }^{28} \mathrm{Si}$ tenemos

\footnotetext{
26 FeldfeBer, Myriam, “¿Es pública la escuela privada..., ob. cit., p. 169.

27 Ibid., pp. 171-175.

28 Observatorio Educativo de la Universidad Pedagógica Nacional, Subvenciones estatales a la educación privada. ¿Quiénes reciben más?, Datos de la Educación, año 1, № 2, octubre de 2018.
} 
en cuenta las pésimas condiciones en las que se encuentra la educación de gestión estatal en Argentina, parece evidente que la política pública de subvención de escuelas privadas confesionales podría generar un efecto de transferencia de alumnos hacia estás últimas (en las cuales, como ya se destacó, no existe protección a la libertad religiosa de los niños). ${ }^{29}$

La importancia de la educación se construye sobre los cimientos de un Estado democrático y participativo. Necesitamos formar a nuestros ciudadanos con los conocimientos elementales para que sean capaces de ser protagonistas de las discusiones de la cosa pública. La obligatoriedad de la educación es la muestra de que ésta constituye un interés esencial para el país y para la comunidad en la que vivimos. Puede decirse que existe un alto grado de consenso sobre la idea de que los niños deben asistir a la escuela, además de porque tienen derecho a hacerlo, porque todos necesitamos que se formen como personas, como ciudadanos, y como actores políticos.

Tanto es así que el artículo $3^{\circ}$ de la Ley de Educación Nacional establece que "La educación es una prioridad nacional y se constituye en política de Estado para construir una sociedad justa, reafirmar la soberanía e identidad nacional, profundizar el ejercicio de la ciudadanía democrática, respetar los derechos humanos y libertades fundamentales y fortalecer el desarrollo económico-social de la Nación." No es necesario establecer distinciones de ningún tipo. La prioridad nacional es en relación a la educación; no es relevante si se trata de una escuela pública o una escuela privada.

Debemos garantizar, en este sentido, la formación educativa desde una óptica de Derechos Humanos, de igual manera para todos los niños, sin importar a qué escuela asisten, lo cual, además, no pueden decidir. No pueden permitirse distinciones arbitrarias basadas en quién gestiona una institución, porque

29 Desde cierto punto de vista, sería plausible pensar que existe una suerte de "encubrimiento" de la enseñanza religiosa a través del subsidio a escuelas confesionales. 
el grupo que debe protegerse por mandato constitucional son todos los niños, sin ningún otro tipo de diferenciación.

\section{Conclusiones}

El fallo "Castillo" de la CSJN constituye un avance desde un punto de vista de neutralidad religiosa del Estado. Sin embargo, deja una gran deuda pendiente en materia de educación y de derechos de la niñez. Establece distinciones arbitrarias entre niños que vulneran el principio de igualdad, sin argumentos sólidos para realizarlas. A partir de algunas aproximaciones que tienen por fin mostrar ciertas incongruencias de la Corte en el precedente en cuestión, se pretendió proponer que no existen argumentos sólidos para defender que la laicidad de la educación debería aplicarse solamente a escuelas públicas.

Luego de un análisis relativo a cuáles son los derechos que entran en juego cuando se habla de educación religiosa, se sostuvo que estos derechos no pueden ser tenidos en cuenta únicamente para quienes van a una escuela de gestión estatal. Cuando hablamos de autonomía personal, de educación liberal, de pensamiento crítico para la formación de ciudadanos, de intimidad, entre otros, no podemos excluir al gran porcentaje de niños que asisten a una escuela privada. En términos de igualdad, para establecer distinciones de este tipo, deberíamos encontrar argumentos profundamente consolidados que permitan argumentar que un niño de una escuela privada no debe gozar del derecho a la libertad religiosa.

El objetivo de este trabajo consistió en desarrollar algunas intuiciones relativas a la incoherencia del argumento de la laicidad únicamente para escuelas de gestión estatal. Lejos de pretender realizar un exhaustivo análisis, se pretende que el presente ensayo sirva como puntapié inicial para discutir un tema poco trabajado y del cual pareciera haber un alto grado de consenso, sobre el punto de que una escuela privada puede enseñar religión a los niños sin ningún tipo de límite. 


\section{Bibliografía}

Faerman, Romina, Ministerio Público Tutelar de la CABA, Las decisiones de los niños, niñas y adolescentes a la luz del principio de autonomía personal, Documento de trabajo $\mathrm{N}^{\circ} 6$.

FeldFeber, Myriam, “¿Es pública la escuela privada? Notas para pensar en el Estado y en la educación" en Perazza, Roxana (Dir.), Mapas y recorridos de la educación de gestión privada en la Argentina, Buenos Aires, Aique, 2012

Gutmann, Amy, Democratic Education, New Jersey, Princeton University Press

Larrosa, Jorge, Pedagogía profana. Estudios sobre lenguaje, subjetividad, formación, Buenos Aires, Ediciones Novedades Educativas, 2000

Nino, Carlos S., Ética y derechos humanos, Buenos Aires, Astrea, 2 ed., 1989.

Nino, Carlos S., Fundamentos de Derecho Constitucional, 4ta Ed., Buenos Aires, Astrea, 2013

Observación General No 13 del Comité de Derechos Económicos, Sociales y Culturales de la Organización para las Naciones Unidas sobre la interpretación del Artículo 13 del PIDESC, del 8/12/1999, párr. 28.

Observación General No 22 del Comité de Derechos del Hombre de las Naciones Unidas sobre la interpretación del artículo 18 del PIDESC, del 20/07/1993.

PInEAu, Pablo, "Reprimir y discriminar. La educación en la última dictadura cívico-militar en Argentina (1976-1983)" Educar em Revista, Curitiba, Brasil, n. 51, p. 103-122, 2014. Editora UFPR.

SABA, Roberto, "Igualdad de trato entre particulares", en Lecciones y Ensayos, Departamento de Publicaciones de la Facultad de Derecho de la UBA, N 89, 2011. 